\title{
Ghrelin promotes differentiation of human embryonic stem cells into cardiomyocytes
}

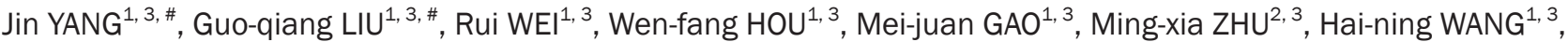 \\ Gui-an $\mathrm{CHEN}^{2,3, *}$, Tian-pei HONG ${ }^{1,3, *}$ \\ ${ }^{1}$ Department of Endocrinology and Metabolism, Peking University Third Hospital, Beijing 100191, China; ${ }^{2}$ Reproductive Medical Center, \\ Peking University Third Hospital, Beijing 100191, China; ${ }^{3}$ Clinical Stem Cell Research Center, Peking University Third Hospital, Beijing \\ 100191, China
}

\begin{abstract}
Aim: Ghrelin is involved in regulating the differentiation of mesoderm-derived precursor cells. The aim of this study was to investigate whether ghrelin modulated the differentiation of human embryonic stem (hES) cells into cardiomyocytes and, if so, whether the effect was mediated by growth hormone secretagogue receptor $1 \alpha$ (GHS-R $1 \alpha)$.

Methods: Cardiomyocyte differentiation from hES cells was performed according to an embryoid body (EB)-based protocol. The cumulative percentage of beating EBs was calculated. The expression of cardiac-specific markers including cardiac troponin I (cTnl) and $\alpha$-myosin heavy chain $(\alpha-\mathrm{MHC})$ was detected using RT-PCR, real-time PCR and Western blot. The dispersed beating EBs were examined using immunofluorescent staining.

Results: The percentage of beating EBs and the expression of cTnl were significantly increased after ghrelin (0.1 and $1 \mathrm{nmol} / \mathrm{L})$ added into the differentiation medium. From 6 to $18 \mathrm{~d}$ of differentiation, the increased expression of cTnl and $\alpha$-MHC by ghrelin (1 nmol/L) was time-dependent, and in line with the alteration of the percentages of beating EBs. Furthermore, the dispersed beating EBs were double-positively immunostained with antibodies against cTnl and $\alpha$-actinin. However, blockage of GHS-R1 $\alpha$ with its specific antagonist D-[lys ${ }^{3}$ ]-GHRP-6 $(1 \mu \mathrm{mol} / \mathrm{L})$ did not alter the effects of ghrelin on cardiomyocyte differentiation.
\end{abstract}

Conclusion: Our data show that ghrelin enhances the generation of cardiomyocytes from hES cells, which is not mediated via GHS-R1 $\alpha$.

Keywords: cardiomyocytes; differentiation; ghrelin; embryonic stem cells

Acta Pharmacologica Sinica (2011) 32: 1239-1245; doi: 10.1038/aps.2011.79; published online 1 Aug 2011

\section{Introduction}

It is well known that human embryonic stem (hES) cells, one of the most promising pluripotent stem cell source for the treatment of many incurable diseases, can differentiate into the majority of cell types including cardiomyocytes ${ }^{[1-3]}$. In 2001, Kehat and the colleagues firstly reported a spontaneous embryoid body (EB)-based protocol of hES cell differentiation into cardiomyocytes ${ }^{[2]}$. In that study, the spontaneously beating areas appeared in only $8.1 \%$ of EBs, indicating the efficiency of differentiation was typically low. It is therefore preferable to use specific differentiation agents to elevate the efficiency of cardiomyocyte differentiation from hES cells. To date, however, only a few factors, such as bone morphogenetic

\footnotetext{
"These authors contributed equally to this work.

* To whom correspondence should be addressed.

E-mail tpho66@bjmu.edu.cn (Tian-pei HONG); chenguian@bjmu.edu.cn (Gui-an CHEN)

Received 2011-03-01 Accepted 2011-05-18
}

proteins (BMPs) ${ }^{[4-6]}$, fibroblast growth factors (FGFs ${ }^{[7]}$ or members of Wnt family ${ }^{[8]}$, have been shown to enhance cardiomyocyte differentiation from hES cells. Therefore, identifying new cardiogenic factors is absolutely necessary to establish a more efficient cardiomyocyte differentiation protocol of hES cells.

Ghrelin, a 28-amino-acid peptide identified as the first endogenous ligand for the growth hormone secretagogue receptor (GHS-R) ${ }^{[9]}$, is found mainly in stomach and hypothalamus where it exercises biological activities such as regulating food intake and stimulating the release of growth hormone $(\mathrm{GH})^{[9-12]}$. It has been recently reported that ghrelin is also synthesized and secreted by cardiomyocytes ${ }^{[13]}$ and that ghrelin treatment inhibits cell death and apoptosis and promotes cell proliferation in cardiomyocytes ${ }^{[14]}$. In addition, several studies have shown that ghrelin is involved in regulating the differentiation of mesoderm-derived precursor cells including premyocyte $^{[15,16]}$, osteoblast ${ }^{[17]}$, and preadipocyte ${ }^{[18,19]}$ either in vivo or in vitro. However, whether ghrelin has a potential role in the differentiation of cardiomyocytes derived from stem 
cells remains to be clarified.

In the present study, we investigated whether ghrelin affected the differentiation of hES cells into cardiomyocytes and, if so, whether GHS-R1a mediated the effect of ghrelin. Our data show for the first time that ghrelin significantly enhances the generation of beating cardiomyocytes from hES cells, which is likely mediated via an unidentified subtype of ghrelin receptor rather than GHS-R1a. Therefore, our study might provide an insight to create an effective strategy for promoting differentiation of hES cells into cardiomyocytes.

\section{Materials and methods Regents}

KnockOut $^{\mathrm{TM}}$ Dulbecco's modified Eagle's medium (DMEM), $\mathrm{KnockOut}^{\mathrm{TM}}$ serum replacement (SR), nonessential amino acids solution (NEAA), L-glutamine, $\beta$-mercaptoethanol, collagenase IV and DMEM/F12 medium were purchased from Invitrogen (Carlsbad, CA, USA). Fetal bovine serum (FBS) was obtained from Hyclone (Logan, UT, USA). Dispase, gelatin, penicillin, streptomycin and $D$-[lys $\left.{ }^{3}\right]$-GHRP-6 $\left(D-\right.$ lys $^{3}$ growth hormone release peptide-6) were purchased from Sigma (St Louis, MO, USA). Basic fibroblast growth factor (bFGF) was purchased from PeproTech (Rocky Hill, NJ, USA). Collagenase B was purchased from Roche (Basel, Switzerland). Human ghrelin was purchased from Phoenix (Burlingame, CA, USA). Paraformaldehyde, phosphate buffered saline (PBS), triton X-100, 4',6-diamidino-2-phenylindole (DAPI) and normal goat serum were purchased from Zhongshan Biotechnology Company (Beijing, China). Rabbit anti-cardiac troponin I (cTnI) antibody and rabbit anti-a-MHC antibody were purchased from Sigma. Mouse anti-Oct4 antibody and mouse anti-a-actinin antibody were obtained from Chemicon (Temecula, CA, USA). Mouse anti- $\beta$-actin antibody, tetramethyl rhodamine isothiocyanate (TRITC)-conjugated goat anti-rabbit IgG and fluorescein isothiocyanate (FITC)-conjugated goat anti-mouse IgG were purchased from Zhongshan Biotechnology Company. IRDye $800 \mathrm{CW}$ conjugated goat anti-rabbit IgG and goat anti-mouse IgG were purchased from LI-COR Biosciences (Lincoln, NE, USA). The primers for RT-PCR and real-time RT-PCR were obtained from Beijing Aoke Biotechnology Company (Beijing, China).

\section{Culture and differentiation of hES cells}

The hES cell line PKU1.1, established by the Reproductive Medical Center of Peking University Third Hospital, was cultured as described previously ${ }^{[20]}$. Briefly, undifferentiated hES cells were propagated on irradiated mouse embryonic fibroblast (MEF) feeder layers in KnockOut ${ }^{\mathrm{TM}}$ DMEM supplemented with $20 \%(v / v)$ KnockOut $^{\mathrm{TM}} \mathrm{SR}, 1 \%(v / v)$ NEAA, $2 \mathrm{mmol} / \mathrm{L}$ L-glutamine, $4 \mathrm{ng} / \mathrm{mL}$ bFGF, $0.1 \mathrm{mmol} / \mathrm{L}$ $\beta$-mercaptoethanol, $50 \mathrm{IU} / \mathrm{mL}$ penicillin, and $50 \mathrm{mg} / \mathrm{mL}$ streptomycin. The cells were passaged every $5-7 \mathrm{~d}$ by incubation in $1 \mathrm{mg} / \mathrm{mL}$ collagenase IV.

For differentiation, the hES cells were dispersed into small clumps by incubation with $1 \mathrm{mg} / \mathrm{mL}$ dispase and were then transferred to ultra low attachment 6-well plates (Corning,
NY, USA) for 5-d suspension culture to form EBs in the differentiation medium DMEM/F12 medium containing 20\% (v/v) FBS, $2 \mathrm{mmol} / \mathrm{L}$ L-glutamine, $1 \%(v / v)$ NEAA and $0.1 \mathrm{mmol} / \mathrm{L}$ $\beta$-mercaptoethanol. The medium was changed every day. Human ghrelin was simultaneously added to the differentiation medium at the final concentrations of 0.1 or $1 \mathrm{nmol} / \mathrm{L}$ in the presence or absence of $1 \mu \mathrm{mol} / \mathrm{L} D$-[1ys $\left.{ }^{3}\right]-G H R P-6$, a specific antagonist of GHS-R1a. The formed EBs were then transferred to and plated on $0.1 \%$ gelatin-precoated 96-well plates (Corning) with one EB per well, and cultured for additional $13 \mathrm{~d}$ in the same medium which was changed every $2 \mathrm{~d}$. The plates with attached EB cultures were carefully observed under a phase contrast microscope for the appearance of rhythmic beating areas within EBs, which indicated the cardiomyocyte differentiation. The control group was cultured in the aforementioned medium without ghrelin and/or $D$-[lys $\left.s^{3}\right]$ GHRP-6 throughout the whole differentiation procedure. The numbers of beating EBs and total EBs were counted, and the cumulative percentages of beating EBs were calculated. Four independent experiments were done in each group and at least $100 \mathrm{EBs}$ were included in each experiment.

\section{Immunofluorescent and cytochemical staining}

The hES cells were fixed in $4 \%(v / v)$ paraformaldehyde for 20 min at room temperature (RT) and blocked for $30 \mathrm{~min}$ at RT with $10 \%$ normal goat serum, followed by incubation with mouse anti-Oct 4 antibody $(1: 100)$ at $4{ }^{\circ} \mathrm{C}$ overnight. For immunostaining of differentiated cells, the beating areas within EBs were dissected and dispersed into single cells using $1 \mathrm{mg} / \mathrm{mL}$ collagenase B. Dispersed cells were plated on $0.1 \%$ gelatinprecoated glass coverslips, cultured for additional $2 \mathrm{~d}$ and then immunostained with rabbit anti-cTnI (1:100) and mouse anti- $\alpha$-actinin (1:200) antibodies. After washing, the cells were incubated with the diluted secondary antibodies, TRITCconjugated goat anti-rabbit IgG or FITC-conjugated goat anti-mouse IgG, at RT for $30 \mathrm{~min}$, followed by washing and stained with DAPI. Images were captured under a fluorescent microscope (Nikon, Kanagawa, Japan) or a confocal laser microscope (Carl Zeiss, Oberkochen, Germany). Negative controls were performed by using corresponding isotype sera to replace the primary antibodies.

For cytochemical staining of alkaline phosphatase, the hES cells were fixed by $4 \%$ paraformaldehyde and analysis was determined by cytochemical techniques using 5-bromo-4chloro-3-indolyl phosphate (BCIP)/ nitrotetrazolium blue chloride (NBT) (Vector Labs, Burlingame, CA, USA) as substrates. Images were captured under a phase contrast microscope (Nikon).

\section{RT-PCR and real-time RT-PCR}

Total RNA samples were prepared from undifferentiated hES cells and differentiated EBs with RNeasy Mini Kit (Qiagen, Hilden, Germany) according to the manufacturer's instructions. Total RNA was reversely transcribed into cDNA using First Strand cDNA Synthesis Kit (Fermentas, Burlington, Ontario, Canada). For analysis of GHS-R1a, reverse transcrip- 
tion reactions were conducted by using $1 \mathrm{nmol} / \mathrm{L}$ specific antisense primer $\left(5^{\prime} \text {-CCCAGAAGTCTGAACACTGCCACC- } 3^{\prime}\right)^{[21]}$. The cDNA was then amplified by PCR using Taq Plus PCR Master Mix (Qiagen) or by real-time PCR with an iQ5 realtime PCR detection system (Bio-Rad, Hercules, CA, USA) as described previously ${ }^{[3,22]}$. In real-time RT-PCR analysis, the expression level of each gene at every checkpoint was normalized to the maximal level observed, which was set as $100 \%$. Three tests were performed for each sample at the same time. The primer sequences and PCR conditions used in this study are listed in Table 1.

Table 1. Primer sequence, annealing temperature and product size of RTPCR and real-time RT-PCR analyses.

\begin{tabular}{|c|c|c|c|}
\hline Gene & Primer sequence & $\begin{array}{c}\text { Annealing } \\
\text { tempera- } \\
\text { ture }\left({ }^{\circ} \mathrm{C}\right)\end{array}$ & $\begin{array}{l}\text { Product } \\
\text { size } \\
\text { (bp) }\end{array}$ \\
\hline \multicolumn{4}{|l|}{ RT-PCR } \\
\hline cTnl & $\begin{array}{l}\text { Forward: 5'-CCCTGCACCAGCCCCAATCAGA-3' } \\
\text { Reverse: 5'-CGAAGCCCAGCCCGGTCAACT-3' }\end{array}$ & 66 & 233 \\
\hline$\alpha-\mathrm{MHC}$ & $\begin{array}{l}\text { Forward: 5'-GGGCGGGGAAGACTGTGAAC-3' } \\
\text { Reverse: 5'-CCCAGCACGTCAAAGGCACT-3' }\end{array}$ & 66 & 481 \\
\hline Oct4 & $\begin{array}{l}\text { Forward: 5'-GAAGTTAGGTGGGCAGCTTG-3' } \\
\text { Reverse: 5'-AGCTTCCTCCACCCACTTCT-3' }\end{array}$ & 66 & 376 \\
\hline Nanog & $\begin{array}{l}\text { Forward: 5'-ATACCTCAGCCTCCAGCAGA-3' } \\
\text { Reverse: 5'-CAGGACTGGATGTTCTGGGT-3' }\end{array}$ & 62 & 294 \\
\hline GHS-R $1 \alpha$ & $\begin{array}{l}\text { Forward: 5'-CTGCGCTCAGGGACCAGAACCA-3' } \\
\text { Reverse: 5'-GTTGATGGCAGCACTGAGGTAGAA-3' }\end{array}$ & 61 & 205 \\
\hline GAPDH & $\begin{array}{l}\text { Forward: 5'-ACAGTCAGCCGCATCTTCTT-3' } \\
\text { Reverse: 5'-CTGGAAGATGGTGATGGGAT-3' }\end{array}$ & 60 & 289 \\
\hline Real-time & RT-PCR & & \\
\hline cTnl & $\begin{array}{l}\text { Forward: 5'-ACACCGAGAAGGAAAACCG-3' } \\
\text { Reverse: 5'-GAAGGCTCAGCTCTCAAACT-3' }\end{array}$ & 58 & 101 \\
\hline$\alpha-\mathrm{MHC}$ & $\begin{array}{l}\text { Forward: 5'-CAGAGGAGAAAGCTGGCGTC-3' } \\
\text { Reverse: 5'-TTGTCAGCATCTTCGGTGCC-3' }\end{array}$ & 64 & 121 \\
\hline GAPDH & $\begin{array}{l}\text { Forward: 5'-TGCACCACCAACTGCTTAGC-3' } \\
\text { Reverse: 5'-GGCATGGACTGTGGTCATGAG-3' }\end{array}$ & 64 & 87 \\
\hline
\end{tabular}

\section{Western blot}

Cell lysates were extracted from the EBs on d 6, 12, and 18 of differentiation. The proteins were separated by $10 \%$ SDSPAGE, and were electrophoretically transferred to polyvinylidene difluoride membranes. Blots were then done by overnight incubation with rabbit anti-cTnI (1:500), rabbit antia-MHC (1:1000) and mouse anti- $\beta$-actin (1:5000), followed by a reaction with IRDye $800 \mathrm{CW}$ conjugated goat anti-rabbit IgG and goat anti-mouse IgG (1:10 000) for $1 \mathrm{~h}$. Immunocomplexes were visualized with the Odyssey infrared imaging system (LI-COR, Lincoln, NE, USA).

\section{Statistical analysis}

Data are presented as mean \pm SEM. Statistical analysis was assessed by SPSS statistical package (SYSTAT Software Inc,
Chicago, IL, USA) with standard Student's t-test. $P<0.05$ was considered to be statistically significant.

\section{Results}

Differentiation of hES cells into beating EBs

The hES cell line PKU1.1 used in this study had undergone 72 passages, and thus the features of the cells were assessed again here. The karyotype analysis showed that these cells maintained their normal diploid female 46 XX karyotype (data not shown). The hES cells were morphologically characterized by flat and compact colony with small cells having a high nucleus/cytoplasm ratio and prominent nucleoli (Figure 1A). The expression of Oct4 and alkaline phosphatase was observed in hES cell colony (Figure 1B-1E), suggesting that the pluripotent state of hES cells was well maintained in our culture system.

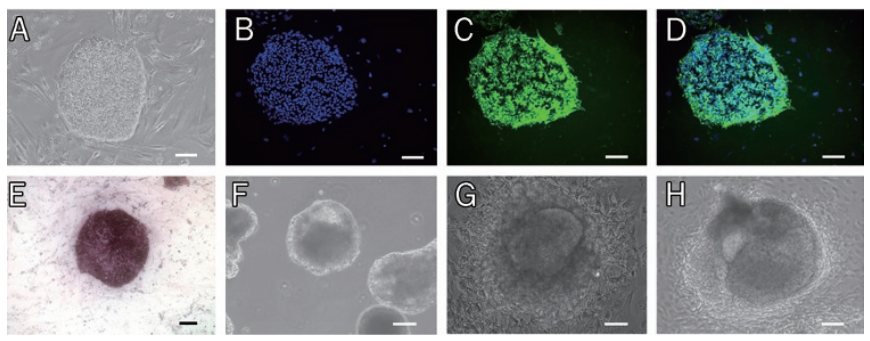

Figure 1. Characterization of hES cells and their differentiation into beating EBs. (A) Undifferentiated hES cell colony under a phase contrast microscope. (B-D) Immunofluorescent staining for Oct4 expression in hES cells: (B) DAPI in blue; (C) Oct4 in green; (D) Merge. (E) Cytochemical staining for alkaline phosphatase in hES cells. (F) Generation of mature EBs characterized by cystic cavities after suspension culture for $5 \mathrm{~d}$. (G) The EBs in adherent culture for further differentiation. (H) Beating EBs observed after d 6 of differentiation culture. Magnification bars represent $100 \mu \mathrm{m}$.

After 5-d suspension culture of hES cells with the differentiation medium, mature EBs as shown by the appearance of cystic cavities were observed (Figure 1F). The EBs were then plated in adherent culture condition for further differentiation. Within $24 \mathrm{~h}$, the EBs attached to the bottom of the plates and the monolayer cells spread out from the EBs (Figure 1G). The three-dimensional beating areas within the attached EBs began to appear in very small proportion of EBs from $1 \mathrm{~d}$ after plating ( $\mathrm{d} 6$ of differentiation). These beating areas, located in the cell mass but not the monolayer cells, were observed and recorded (Figure $1 \mathrm{H}$ ).

\section{Effects of ghrelin on derivation of beating EBs from $\mathrm{hES}$ cells}

The cumulative percentages of beating EBs among total EBs increased gradually after plating on adherent culture plates until d 18 of differentiation and then maintained at that level. The percentages of beating EBs on 18 of differentiation were $12.2 \%$ and $18.6 \%$ respectively in the groups treated with 0.1 and $1 \mathrm{nmol} / \mathrm{L}$ ghrelin, which were markedly higher than 9.5\% in the control group (Figure 2A). On d 12 and 18 of differen- 

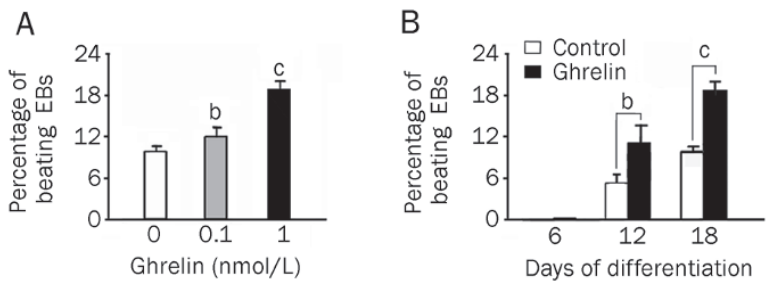

Figure 2. Effects of ghrelin on the generation of beating EBs. (A) Doseeffects of ghrelin on the percentage of beating EBs as evaluated on d 18 of differentiation. (B) Time-kinetic effects of $1 \mathrm{nmol} / \mathrm{L}$ ghrelin on the percentages of beating EBs as evaluated on d 6, 12 and 18 of differentiation. Each value represents the mean \pm SEM. $n=4 .{ }^{b} P<0.05$, ${ }^{\mathrm{c}} P<0.01$ vs control group.

tiation, the percentages of beating EBs were 4.9\% and 9.5\% respectively in control group, which were markedly increased to $11.1 \%$ and $18.6 \%$ by treatment with $1 \mathrm{nmol} / \mathrm{L}$ ghrelin (Figure 2B). These results indicated that ghrelin increased the percentage of beating EBs derived from hES cells in a doseand time-dependent manner.

Effects of ghrelin on the expression of cardiac-specific markers in the differentiated EBs

In RT-PCR analysis, genes encoding cTnI and a-myosin heavy chain (a-MHC), two cardiac structural proteins, were expressed in the EBs on d 18 of differentiation. The mRNA levels of both cTnI and a-MHC were upregulated by $1 \mathrm{nmol} / \mathrm{L}$ ghrelin. On the other hand, the pluripotential markers Oct4 and Nanog, which were highly expressed in the undifferentiated hES cells, were markedly reduced in the differentiated EBs (Figure 3A). Real-time RT-PCR analysis showed that cTnI mRNA level was significantly upregulated by 0.1 and 1 nmol/L ghrelin (Figure 3B). Furthermore, the mRNA levels of cTnI and a-MHC, which were gradually increased from d 6 to $\mathrm{d} 18$ of differentiation in control group, were much higher in the group treated with $1 \mathrm{nmol} / \mathrm{L}$ ghrelin on $\mathrm{d} 12$ and 18 of differentiation (Figure 3C and 3D). Western blot analysis also showed that the protein levels of cTnI and a-MHC were upregulated by $1 \mathrm{nmol} / \mathrm{L}$ ghrelin (Figure $3 \mathrm{E}$ and $3 \mathrm{~F}$ ). It was noteworthy that the time-kinetic effects on the mRNA and protein levels of the cardiac-specific markers were in agreement with that on the percentages of beating EBs (Figure 2B and $3 \mathrm{C}-3 \mathrm{~F}$ ).

For further identification of cardiomyocyte differentiation, the dispersed cells grown on glass coverslips were assessed by immunofluorescent staining. These cells were doublepositively immunostained with antibodies against both cTnI and a-actinin. Moreover, the alignment of a-actinin staining displayed organized sarcomeric striation pattern (Figure 3G). These results indicated that the beating areas within the differentiated EBs consisted of cardiomyocytes.

Effects of GHS-R1 $\alpha$ blockage on the cardiomyocyte differentiation of hES cells induced by ghrelin

RT-PCR analysis showed that GHS-R1a mRNA was barely detectable in the undifferentiated hES cells and was gradually increased in the EBs from d 6 to $\mathrm{d} 18$ of differentiation (Figure 4A). Therefore, the possible role of GHS-R1a in the cardiomyocyte differentiation was tested by adding its specific antagonist $D$-[lys $\left.{ }^{3}\right]-G H R P-6$. On d 18 of differentiation, the promoting effects of $1 \mathrm{nmol} / \mathrm{L}$ ghrelin on the percentage of beating EBs and the mRNA expression of cTnI were not

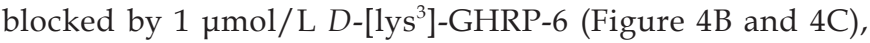
indicating that the induction of cardiomyocyte differentiation of hES cells caused by ghrelin was not mediated via GHS-R1a.

\section{Discussion}

Ghrelin is a newly identified gut-brain peptide and has been demonstrated to have a wide range of functions including stimulation of GH release, control of energy metabolism and regulation of pancreatic hormone release ${ }^{[9,11,12,23]}$. Recently, it has been demonstrated that ghrelin also has a cardioprotective activity via several mechanisms. Ghrelin inhibited apoptosis induced by high glucose and high free fatty acid in isolated mouse and rat cardiomyocytes ${ }^{[14]}$. In pressureoverload chronic heart failure rats, left ventricular remodeling and dysfunction were improved by treatment with ghrelin ${ }^{[24]}$. A pilot clinical study also showed that treatment with ghrelin improved left ventricular function and exercise capacity in the patients with severe chronic heart failure ${ }^{[25]}$. However, little is known about the role of ghrelin in the heart development during embryogenesis or in the differentiation of cardiomyocytes from stem cells.

The EB-based differentiation strategy, which imitates the early development of embryo, is a basic method to initiate cardiomyocyte differentiation of hES cells ${ }^{[2]}$. The role of ghrelin in cardiomyogenesis was investigated on the basis of this strategy in the present study. Our data showed that the percentage of beating EBs and the expression of cardiac-specific markers cTnI and a-MHC in the differentiated EBs were increased by treatment with ghrelin. These results suggested that ghrelin was a potent differentiation-promoting factor for hES cell-derived cardiomyocytes.

Numerous studies have shown that ghrelin directly regulates the differentiation of several mesoderm-derived precursor cells. Ghrelin promoted proliferation and differentiation in osteoblastic cell lines and cultured primary osteoblasts in vitro $^{[17]}$. An in vivo study showed that administration of ghrelin stimulated osteogenesis of intramembranous bone and improved the repair of calvarial bone defect in rats ${ }^{[26]}$. Ghrelin was shown to promote differentiation of isolated rat primary preadipocytes. In GH-deficient dwarf $(d w / d w)$ rats, the infusion of ghrelin induced adipogenesis in bone marrow by a direct action ${ }^{[19]}$. Ghrelin also increased the differentiation of premyocytes into myocytes in a mouse premyocyte cell line $\mathrm{C} 2 \mathrm{C} 12^{[16]}$. Taken together, all the results suggest that ghrelin is a differentiation-regulating factor for mesoderm-derived tissue cells.

To elucidate whether ghrelin is involved in derivation of cardiomyocyte which is also derived from mesoderm, the cardiomyocyte differentiation of hES cells was used in the present 
A

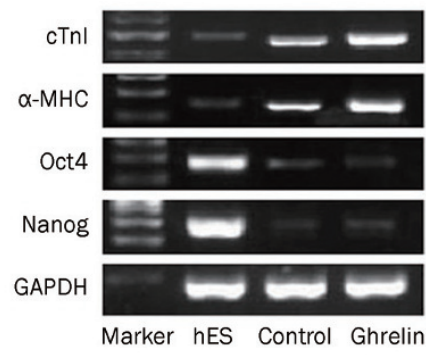

D

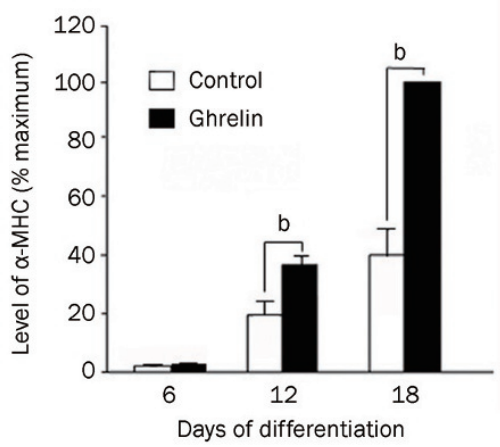

G
B

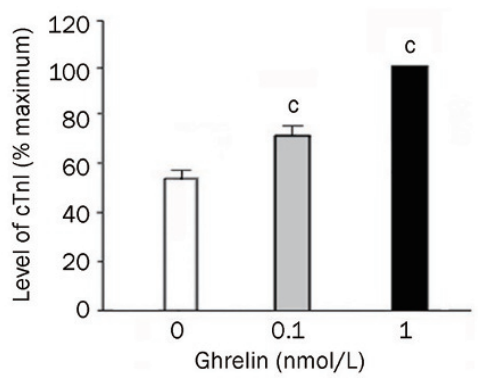

E
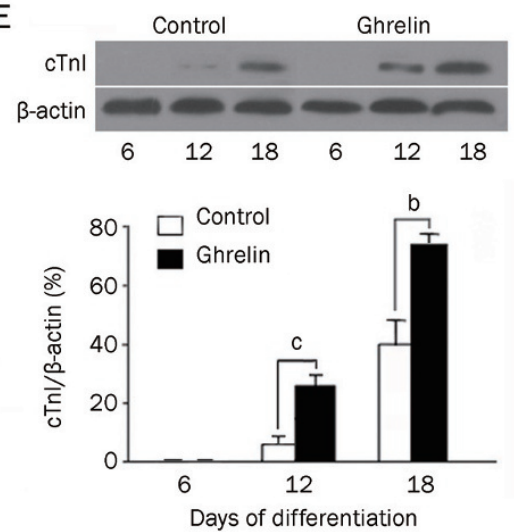

cTnl
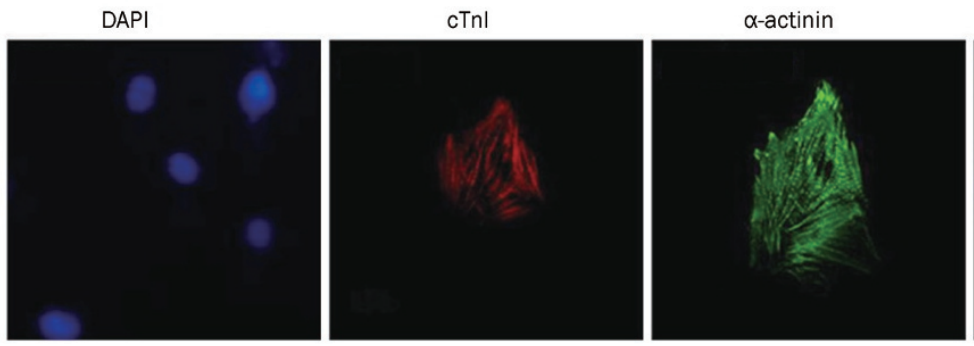

C

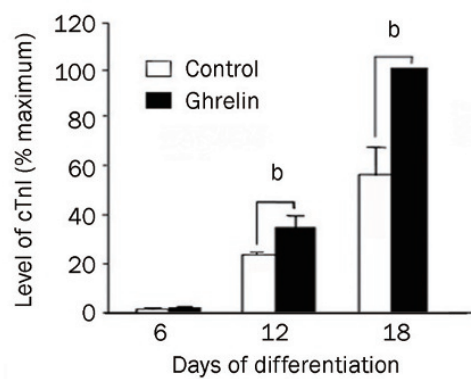

F
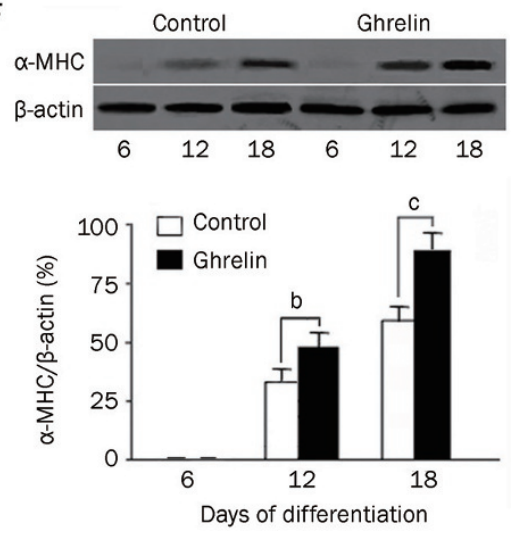

Merge

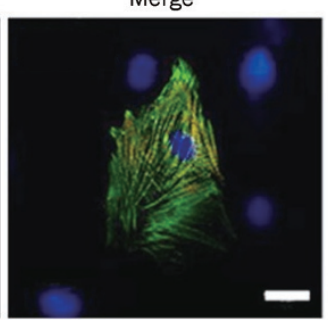

Figure 3. Effects of ghrelin on the expression of cardiac-specific markers in differentiated EBs. (A) RT-PCR analysis for mRNA level in the undifferentiated hES cells and the EBs treated with or without $1 \mathrm{nmol} / \mathrm{L}$ ghrelin on d 18 of differentiation. (B) Dose-effects of ghrelin on cTnl mRNA expression as evaluated by real-time RT-PCR analysis on d 18 of differentiation. (C, D) Time-kinetic effects of $1 \mathrm{nmol} / \mathrm{L}$ ghrelin on the mRNA expression of cardiac-specific markers as evaluated by real-time RT-PCR analysis in the EBs on d 6, 12 and 18 of differentiation: (C) cTnl; (D) $\alpha$-MHC. The maximum expression levels which were expressed as $100 \%$ were used to normalize the expression levels at other time points. (E, F) Time-kinetic effects of $1 \mathrm{nmol} / \mathrm{L}$ ghrelin on the protein expression of cardiac-specific markers as evaluated by Western blot analysis in the EBs on d 6, 12 and 18 of differentiation: (E) cTnl; (F) $\alpha$-MHC. The histograms show the percentage of target protein expression to $\beta$-actin, which served as an internal standard. Each value represents the mean \pm SEM. ${ }^{b} P<0.05,{ }^{c} P<0.01$ vs control group. $n=4$. (G) Confocal images of immunofluorescent staining for $c T n l$ (red) and $\alpha$-actinin (green) in the dispersed cells from the beating areas within EBs. Magnification bar represents $20 \mu \mathrm{m}$.

study. Because of unlimited proliferation capacity and multipotency, hES cells may be one of the most attractive stem cell source used in the field of regenerative medicine in the future. However, an efficient in vitro cardiomyocyte differentiation protocol must be established before hES cells could be clinically available in treating heart diseases. Up to now, only a few factors have been demonstrated to have a role in promoting cardiomyocyte differentiation from hES cells. In 2006, a study reported that the expression of cardiac-specific markers including cTnI and a-MHC was promoted by the combination of BMP-4 and activin A in the N2/B27-chemically defined medium used in hES cell differentiation ${ }^{[4]}$. However, the ratio of beating EBs was not analyzed in that study. Another study assessed cardiomyocyte differentiation from two hES cell lines in low FBS-containing medium in the presence of BMP-2, in which the cumulative percentages of beating EBs were only $8.75 \%$ and $6.94 \%$ respectively by d 28 of differentiation ${ }^{[6]}$. In our study, both real-time RT-PCR and Western blot analyses revealed that the expression of cTnI and a-MHC in the ghrelin-treated group was markedly higher than that in control group. Furthermore, our data showed that the percentages of beating EBs on d 12 and 18 of differentiation were $4.9 \%$ and $9.5 \%$ respectively in control group, which were increased to $11.1 \%$ and $18.6 \%$ by treatment with $1 \mathrm{nmol} / \mathrm{L}$ ghrelin. It was worth noting that the increment in the percentages of beating EBs was in accordance with the alteration in the expression 
A

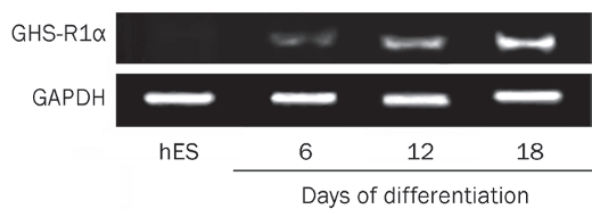

B

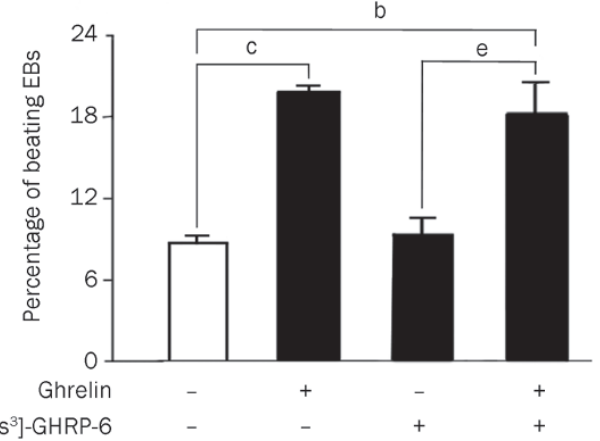

C

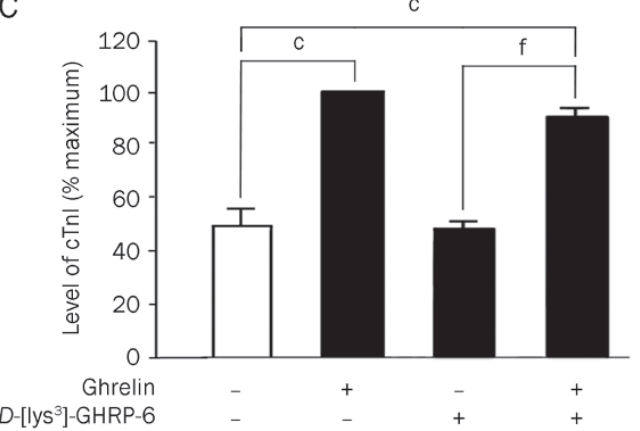

Figure 4. Effects of GHS-R $1 \alpha$ blockage on the cardiomyocyte differentiation of hES cells induced by ghrelin. (A) RT-PCR analysis for GHS-R $1 \alpha$ expression in the undifferentiated hES cells and the EBs on $d 6,12$, and 18 of differentiation. (B) Effects of $1 \mathrm{nmol} / \mathrm{L}$ ghrelin on the percentages of beating EBs as evaluated on d 18 of differentiation in the presence or absence of a specific GHS-R1 $\alpha$ antagonist $D$-[lys ${ }^{3}$ ]-GHRP-6 $(1 \mu \mathrm{mol} / \mathrm{L})$. (C) Effects of $1 \mathrm{nmol} / \mathrm{L}$ ghrelin with or without $1 \mu \mathrm{mol} / \mathrm{L} D$-[lys ${ }^{3}$ ]-GHRP-6 on cTnl expression as evaluated by real-time RT-PCR analysis in the EBs on $\mathrm{d} 18$ of differentiation. Each value represents the mean \pm SEM. $n=4$. ${ }^{\mathrm{b}} P<0.05,{ }^{\mathrm{c}} P<0.01$ vs control group; ${ }^{\mathrm{e}} P<0.05,{ }^{\mathrm{f}} P<0.01$ vs $D$-[lys $\left.{ }^{3}\right]$-GHRP-6 group.

of cTnI and a-MHC. Our data suggest that ghrelin markedly enhances the yield of cardiomyocyte differentiation from hES cells.

GHS-R1a is the functional ghrelin receptor and ghrelin exerts its biological functions via activation of the receptor subtyp $\mathrm{e}^{[9]}$. In the present study, GHS-R1a was expressed in the differentiated EBs. However, GHS-R1a blockage by $D$-[1ys $\left.{ }^{3}\right]-$ GHRP-6 did not alter the promoting effects of ghrelin on the percentage of beating EBs and the expression of cTnI, suggesting that the induction of cardiomyocyte differentiation of hES cells resulted from ghrelin stimulation was likely mediated via an unidentified subtype of ghrelin receptor rather than GHSR1a. Moreover, our preliminary study showed that mitogen- activated protein kinase (MAPK) pathway was involved in the action of ghrelin (data not shown). Clearly, additional studies are needed to investigate the role of the MAPK signaling in the cardiomyocyte differentiation induced by ghrelin.

In conclusion, the present study show for the first time that ghrelin significantly enhances the generation of beating EBs and the expression of cardiac-specific markers in the differentiated EBs generated from hES cells, indicating that ghrelin promotes the differentiation of hES cells into myocardial cells. Therefore, ghrelin may serve as a useful factor for an effective method in the induction of cardiomyocyte differentiation from hES cells, which may contribute to cardiomyocyte-based regenerative medicine.

\section{Acknowledgements}

This work was supported by grants from the Chinese National 863 Program (2006AA02A112), the National Natural Sciences Foundation of China (№ 30771032, 30700879, 81070701, and 81000315), and the Specialized Research Fund for the Doctoral Program of Higher Education (20100001110083). We thank Dr Hong-mei PENG for setting up our hES cell line PKU1.1 for this research; Li CHEN and Zheng MA for their excellent technical assistance; and Hai-yan YU, Gen-hong MAO, and Tianran SONG for their invaluable assistance.

\section{Author contribution}

Jin YANG and Guo-qiang LIU performed most experiments; Jin YANG, Guo-qiang LIU and Tian-pei HONG wrote the manuscript; Rui WEI, Wen-fang HOU, Mei-juan GAO, Mingxia ZHU and Hai-ning WANG contributed to cell culture and provided technical support; Gui-an CHEN and Tian-pei HONG designed the study.

\section{References}

1 Thomson JA, Itskovitz-Eldor J, Shapiro SS, Waknitz MA, Swiergiel JJ, Marshall VS, et al. Embryonic stem cell lines derived from human blastocysts. Science 1998; 282: 1145-7.

2 Kehat I, Kenyagin-Karsenti D, Snir M, Segev H, Gepstein A, Livne E, et al. Human embryonic stem cells can differentiate into myocytes with structural and functional properties of cardiomyocytes. J Clin Invest 2001; 108: 407-14.

3 Xu C, Police S, Rao N, Carpenter MK. Characterization and enrichment of cardiomyocytes derived from human embryonic stem cells. Circ Res 2002; 91: 501-8.

4 Yao S, Chen S, Clark J, Hao E, Beattie GM, Hayek A, et al. Long-term self-renewal and directed differentiation of human embryonic stem cells in chemically defined conditions. Proc Natl Acad Sci U S A 2006; 103: 6907-12.

5 Laflamme MA, Chen KY, Naumova AV, Muskheli V, Fugate JA, Dupras $\mathrm{SK}$, et al. Cardiomyocytes derived from human embryonic stem cells in pro-survival factors enhance function of infarcted rat hearts. Nat Biotechnol 2007; 25: 1015-24.

6 Pal R, Khanna A. Similar pattern in cardiac differentiation of human embryonic stem cell lines, BG01V and ReliCellhES1, under low serum concentration supplemented with bone morphogenetic protein-2. Differentiation 2007; 75: 112-22.

7 Yook JY, Kim MJ, Son MJ, Lee S, Nam Y, Han YM, et al. Combinatorial 
ALK/Smad and bFGF signals stimulate the differentiation of hESCs into the cardiac lineage. Stem Cells Dev 2011. doi:10.1089/ scd.2010.0392.

8 Tran TH, Wang X, Browne C, Zhang Y, Schinke M, Izumo S, et al. Wnt3a-induced mesoderm formation and cardiomyogenesis in human embryonic stem cells. Stem Cells 2009; 27: 1869-78.

9 Kojima M, Hosoda H, Date Y, Nakazato M, Matsuo H, Kangawa K. Ghrelin is a growth-hormone-releasing acylated peptide from stomach. Nature 1999; 402: 656-60.

10 Gnanapavan S, Kola B, Bustin SA, Morris DG, McGee P, Fairclough P, et al. The tissue distribution of the mRNA of ghrelin and subtypes of its receptor, GHS-R, in humans. J Clin Endocrinol Metab 2002; 87: 2988-91.

11 Ariyasu H, Takaya K, Tagami T, Ogawa Y, Hosoda K, Kamizu T, et al. Stomach is a major source of circulating ghrelin, and feeding state determines plasma ghrelin-like immunoreactivity levels in humans. J Clin Endocrinol Metab 2001; 86: 4753-8.

12 Takaya K, Ariyasu H, Kanamoto N, Iwakura H, Yoshimoto A, Harada M, et al. Ghrelin strongly stimulates growth hormone release in humans. J Clin Endocrinol Metab 2000; 85: 4908-11.

13 Iglesias MJ, Piñeiro R, Blanco M, Gallego R, Diéguez C, Gualillo O, et al. Growth hormone releasing peptide (ghrelin) is synthesized and secreted by cardiomyocytes. Cardiovasc Res 2004; 62: 481-8.

14 Kui L, Weiwei Z, Ling L, Daikun H, Guoming Z, Linuo Z, et al. Ghrelin inhibits apoptosis induced by high glucose and sodium palmitate in adult rat cardiomyocytes through the PI3K-Akt signaling pathway. Regul Pept 2009; 155: 62-9.

15 Zhang W, Zhao L, Mulholland MW. Ghrelin stimulates myocyte development. Cell Physiol Biochem 2007; 20: 659-64.

16 Filigheddu N, Gnocchi VF, Coscia M, Cappelli M, Porporato PE, Taulli R, et al. Ghrelin and des-acyl ghrelin promote differentiation and fusion of C2C12 skeletal muscle cells. Mol Biol Cell 2007; 18: 986-94.

17 Fukushima N, Hanada R, Teranishi H, Fukue Y, Tachibana T, Ishikawa $\mathrm{H}$, et al. Ghrelin directly regulates bone formation. J Bone Miner Res
2005; 20: 790-8.

18 Choi K, Roh SG, Hong YH, Shrestha YB, Hishikawa D, Chen C, et al. The role of ghrelin and growth hormone secretagogues receptor on rat adipogenesis. Endocrinology 2003; 144: 754-9.

19 Thompson NM, Gill DA, Davies R, Loveridge N, Houston PA, Robinson IC, et al. Ghrelin and des-octanoyl ghrelin promote adipogenesis directly in vivo by a mechanism independent of the type 1a growth hormone secretagogue receptor. Endocrinology 2004; 145: 234-42.

20 Hongmei P, Guian C. Serum-free medium cultivation to improve efficacy in establishment of human embryonic stem cell lines. Hum Reprod 2006; 21: 217-22.

21 Gaytan F, Morales C, Barreiro ML, Jeffery P, Chopin LK, Herington AC, et al. Expression of growth hormone secretagogue receptor type 1a, the functional ghrelin receptor, in human ovarian surface epithelium, mullerian duct derivatives, and ovarian tumors. J Clin Endocrinol Metab 2005; 90: 1798-804.

22 Zhang L, Hu J, Hong TP, Liu YN, Wu YH, Li LS. Monoclonal side population progenitors isolated from human fetal pancreas. Biochem Biophys Res Commun 2005; 333: 603-8.

23 Lee HM, Wang G, Englander EW, Kojima M, Greeley GH Jr. Ghrelin, a new gastrointestinal endocrine peptide that stimulates insulin secretion: enteric distribution, ontogeny, influence of endocrine, and dietary manipulations. Endocrinology 2002; 143: 185-90.

24 Xu XB, Pang JJ, Cao JM, Ni C, Xu RK, Peng XZ, et al. GH-releasing peptides improve cardiac dysfunction and cachexia and suppress stress-related hormones and cardiomyocyte apoptosis in rats with heart failure. Am J Physiol Heart Circ Physiol 2005; 289: H1643-51.

25 Nagaya N, Moriya J, Yasumura Y, Uematsu M, Ono F, Shimizu W, et al. Effects of ghrelin administration on left ventricular function, exercise capacity, and muscle wasting in patients with chronic heart failure. Circulation 2004; 110: 3674-9.

26 Deng F, Ling J, Ma J, Liu C, Zhang WZ. Stimulation of intramembranous bone repair in rats by ghrelin. Exp Physiol 2008; 93: 872-9. 